\title{
Differences in Patient Characteristics between Spasmodic Dysphonia and Vocal Tremor
}

\author{
Hee Young Son (1) \\ Department of Otorhinolaryngology, Dongnam Institute of Radiological \& Medical Sciences, Busan, Korea \\ 연축성 발성장애와 음성 진전 환자의 감별
}

손희영

동남권원자력의학원 이비인후과

Spasmodic dysphonia, essential tremor, and vocal tremor related with Parkinson's disease are different disorders showing fairly similar symptoms such as difficulty in the speech onset, and tremble in the voice. However, the cause and the resulting treatment of these diseases are different. Spasmodic dysphonia is a vocal disorder characterized by spasms of the laryngeal muscles during a speech, invoking broken, tense, forced, and strangled voice patterns. Such difficult-to-treat dysphonia disease is classified as central-origin-focal dystonia, of a yet unknown etiology. Its symptoms arise because of intermittent and involuntary muscle contractions during speech. Essential tremor, on the other hand, is characterized by a rhythmic laryngeal movement, resulting in alterations of rhythmic pitch and loudness during speech or even at rest. Severe cases of tremor may cause speech breaks like those of adductor spasmodic dysphonia. In the case of hyper-functional tension of vocal folds and accompanying tremors, it is necessary to distinguish these disorders from muscular dysfunction. A diversified assessment through the performance of specific speech tasks and a thorough understanding for the identification of the disorder is necessary for accurate diagnosis and effective treatment of patients with vocal tremors.

Keywords Spasmodic dysphonia; Vocal tremor; Differential diagnosis.

\section{서 론}

신체 일부의 근긴장 이상으로 인해 발생하는 떨림은 고령에서 종종 관찰할 수 있으며, 여러 가지 원인에 따라 다양한 부위에 발생한다. 발화의 시작이 어렵고 떨리는 음성은 삶의 질을 상당히 저하시키며 증상의 정도에 따라 정상적인 생활을 어렵게 할 수 있다. 그러나 다른 음성 질환에 비해 유병률이 적고, 비슷한 증상을 호소하는 질병이 다수인 점으로 인해 진단에 어려움이 있다. 본 글에서는 이러한 증상을 보이는 대표적인 질환인 연축성 발성장애에 대해 알아보고, 유사한 질환과의 감별 사항을 정리해보고자 한다.
Received March 11, 2021

Revised March 25, 2021

Accepted March 26, 2021

\section{Corresponding Author}

Hee Young Son, MD, PhD Department of Otorhinolaryngology, Dongnam Institute of Radiological \& Medical Sciences,

40 Jwadong-gil, Jangan-eup,

Busan 46033, Korea

Tel $+82-51-720-5287$

Fax $+82-51-720-5914$

E-mail hyson79@gmail.com

\section{ORCID iD}

Hee Young Son (D)

https://orcid.org/0000-0002-2845-1423

This is an Open Access article distributed under the terms of the Creative Commons Attribution Non-Commercial License (https://creativecommons.org/ licenses/by-nc/4.0) which permits unrestricted non-commercial use, distribution, and reproduction in any medium, provided the original work is properly cited. 


\section{본 론}

\section{발성과 관련된 신경조절 체계}

정상적인 발성을 위해서는 후두운동 중추에서 말단의 후두 근육으로 이어지는 일련의 신경조절 체계가 중요하며, 분노와 같은 단순한 자발적 발성에서부터 다양한 언어를 사용하는 인간의 발성은 매우 복잡한 신경전달 과정을 거친다[1,2]. 고 위 운동조절 기능을 하는 대뇌 피질은, 발성과 관련된 다양한 뇌 영역들 간의 연결이 넓게 공유되며 매우 복잡하다. 일차 운동 피질, 전운동과 보완운동 영역, 좌반구의 브로카 영역을 포함하는 전두엽의 대뇌 피질 영역은 음성 산출에 상당히 중 요하다. 특히 일차 운동 피질 내 특수 영역을 후두발성 영역 으로 정의하고 있으며, 기능적 자기공명영상 소견에 기초하여, 구두와 비구두 후두음 및 성대 움직임 전반에 관여하는 것으 로 밝혀졌다. 위치는 궁상핵, 중심고랑 및 실비우스 열개에 의 해 구획될 수 있으며, 자발적 발성과 관련이 있어 이 부위에 병 변이 발생하면 실어증이나 실행증 등이 발생할 수 있다[2-6].

피질연합 영역에서 계획된 발성에 관한 정보는 피질-기저 핵-시상-피질회로를 통해 소뇌로 보내지며, 말을 하기 위한 근육의 운동 범위, 속도, 힘 등을 조절하는 데 중요한 역할을 한다[2,5,7].

피질하부에서는 전방 대상회, 복외측 및 후외측 시상하부 핵과 해마, 편도핵 그리고 중뇌 영역의 수도주위회백질, 팔주 위핵, 청반 등이 발성에 관여하고 있으며, 분노, 웃음 등 감정 상태에도 영향을 받는다. 뇌신경에 의한 두경부와 관련된 근 육 운동은 대뇌 피질에서 뇌간으로 가는 신경 다발인 피질연 수로를 통해 지배된다[5,6,8]. 뇌간은 중뇌, 뇌교 및 연수를 총 칭하는 것으로, 고위 운동 영역과 의문핵에 존재하는 하위운 동뉴런 사이에 중요한 연결 통로 역할을 한다. 의문핵은 후두 운동뉴런을 포함하는 핵집단으로 정의되며, 인두와 후두의 골격근을 지배하는 하위운동뉴런의 축삭이 부신경, 미주신 경 및 설인신경을 형성한다. 수도주위회백질은 고위 피질과 피질하 운동 중추에서의 입력을 조정하고, 의문핵에서 후두 내전근 하위운동뉴런을 효과적으로 활성화하는 데 핵심적인 역할을 한다. 기본적인 호흡과 호흡 노력, 성대 내전과 성대 긴장과 같이 발성을 비롯 연하 및 기침 등에 필요한 후두운 동 패턴 조정에 필수적이다. 해당 부위에 병변이 발생하면 언 어장애가 발생할 수 있다[1,5,7]. 기저핵은 피질하 추체외로계 를 통해 근육 간의 협응 운동 등 섬세한 운동을 조절하며, 파 킨슨 환자에서 해당 부위의 기능 저하가 종종 발견되며 특유 의 떨림을 유발한다. 대뇌피질에서 기저핵, 뇌간까지의 상위 운동뉴런은 근육의 수축과 이완을 담당하지만, 기저핵과 뇌 간에서 기시하여 후두 근육에 종말부를 형성하는 하위운동
뉴런은 근육의 수축에만 관여한다. 따라서 상위운동뉴런의 손상은 근육의 긴장을 초래하며, 하위운동뉴런의 손상은 근 육의 이완을 유발할 수 있다[3,5,7-9].

소뇌는 수의적 운동을 조절하며, 근육 긴장도 및 근육의 협 동 작용과 관련이 있어, 소뇌의 손상은 운동실조증이 유발될 수 있으며, 이와 관련된 음성장애도 발생할 수 있다[1,5,7].

발성과 관련된 신경조절 체계에 관한 이해는 과활동성 또는 저활동성 음성장애를 보이는 질환에 대한 정확한 진단과 치 료에 도움을 줄 수 있다. 이와 함께, 뇌졸중, 파킨슨병, 다발성 경화증 및 중증 근무력증 등 기저 신경학적 질환에서 후두 근신경을 침범하여 발성장애를 호소하는 환자, 성대 부전 및 마비 등 다양한 신경학적 발성장애 환자 진단과 치료에 도움 이 된다[2,5,10,11].

본 종설에서 다루는 연축성 발성장애와 음성 진전은 근육 운동조절 이상으로 인해 부적절한 근육 긴장으로 발생하는 것으로, 상위운동뉴런의 문제가 원인으로 생각되고 있다.

\section{연축성 발성장애}

연축성 발성장애는 1871년 Traube가 “경직형(spastic)의 심 인성 쉰목소리”로 처음 보고한 후, 1980년대까지 과긴장되고 떨리거나 끊김을 보이는 발성장애 환자 중 다른 원인을 모두 배제한 후에도 특별한 병변이 보이지 않을 때 진단되는 질병 이었다[2,8,10]. 신경학적 기능장애로 분류되면서, 후두에 국 한되어 발생한 근긴장 이상(focal dystonia)으로 인해 후두 근육의 불수의적인 수축을 유발하는 질병으로 정의되었다. 신경핵 상부 병변으로 인한 다른 근육의 경직이 없고, 근전도 상 추체장애가 동반되지 않으며, 갑자기 단시간 내 후두에만 국한되는 불규칙적인 이상으로 인해 연축성(spasmodic) 발성 장애로 명명되었다[2,5,12,13].

30 대와 50 대 성인, 주로 여성에서 더 빈번하게 발생하며 점 진적으로 진행하여 만성 질환의 양상을 가진다. 스트레스 상 황에서 증상이 더욱 악화되는 경향을 보인다. 술이나 신경안 정제 복용 시 일부 증상의 감소도 있다[2,5,14,15].

질환의 원인에 대해서는 아직 뚜렷하게 밝혀지지 않았지만, 대화 중 후두 근육을 조절하는 중추신경계 이상으로 발생한 국소 근긴장 이상으로 신경학적 요인이 가장 대표적인 원인이 며, 심리적인 원인이 뚜렷하지만 신경학적 이상 소견이 보이지 않는 경우, 그리고 특발성으로 나눌 수 있다. 최근 여러 연구 들에서 대뇌의 기질적인 변화와 영상 기술을 이용한 신경학 적 원인 감별이 이뤄지고 있으며, 양반구의 다병소적 손상, 좌 대뇌반구의 전두엽과 피질하 구조의 상위운동신경 및 시상과 기저핵, 복외측 피각 등의 관련성이 제기되었다. 특히 기저핵 과 연관성이 높은 것으로 알려져 있으며, 좌측 선조체 이상이 
증상 시작을 유발한다는 연구가 있다. 일부 연구에서, 염색 체 9번의 이상으로 인한 유전적 요인에 대해 언급을 하고 있 다[1-3,5].

연축성 발성장애는 특성에 따라 3가지 형태로 분류되며, 내전형과 외전형 및 혼합형으로 나눌 수 있다. 전체 환자의 $80 \%$ 이상을 차지하는 내전형 연축성 발성장애는 발성 중에 불수의적이면서 불규칙적인 과도한 성대 내전으로 인해 스타 카토와 같은 단절이 나타나고 쥐어짜는 듯한 음성 특징을 보 인다. 외전형은 발성 중에 성대의 과도한 외전으로 기식성의 음성 단절이 나타나고 전체적으로 음성이 약해지는 경향을 보인다. 혼합형은 내전형과 외전형의 두 가지 특성이 한 환자 에게서 모두 보이는 경우에 해당한다[4,12,16,17].

내시경 및 객관적인 음성 검사가 발전하기 이전까지는 대부 분 심리적 원인으로 인한 질환 혹은 특징적인 음성 특성을 보 이지만 관련 질환을 모두 배제하였을 때 연축성 발성장애로 진단하였다[10,18]. 90년대 이후 스트로보스코피와 발전된 굴 곡 내시경 및 다면음성분석 프로그램 등 과학적으로 발전된 음성 검사 기구가 보급되면서 GRBAS와 내시경상 성대 긴장 도의 변화와 움직임 관찰 및 음성 검사상 발성 효율 저하, 기 본주파수, 잡음 대 조화음비, 주파수 변동률 및 진폭 변동률 의 증가 등으로 진단하였다[14,19].

2008년 Ludlow 등은 연축성 발성장애 진단에 대한 세 단계 의 가이드라인을 선별 검사로서 증상을 중심으로 하는 possi$\mathrm{ble}$, 음성 검사로 발성 특징으로 평가하는 probable, 그리고 후두 내시경 검사 등으로 진단을 하는 definite로 나누어 제 시하였다. 첫 단계는 관련 증상이 있는 환자에게 시행하는 선 별 검사로서, 네 가지의 설문조사를 통해 증상의 정도에 대한 두 가지 질문에 대한 긍정적인 답변 및 3 개월 이상의 유병 기 간이 있으면 연축성 발성장애를 가질 가능성이 있는 것으로 (possible) 판단하고 다음 진단 검사 단계로 넘어갈 수 있다. 이 단계에서 울음이나 웃음, 하품 등 비언어적 발성 시 증상 에 대한 질문은 진단 과정에 도움은 되지만, 필수적인 요소는 아니다[2,8]. 두 번째 단계는 임상적인 음성 검사로서 7가지 항목을 음성 전문가와 함께 평가한다. 환자가 쥐어짜는 듯이 힘이 들어간 음성으로 대화 중에는 음성 단절이 일어나지만, 소리를 지르거나 속삭일 때는 단절이 일어나지 않으면 연축 성 발성장애의 가능성이 높다. 특히 내전형과 외전형 그리고 임상적으로 감별이 필요한 과기능성 발성장애를 구별하기 위 해 관련 증상을 잘 유발하는 문장들을 번갈아가며 반복적 으로 정상적인 대화를 하는 음성과 속삭이는 음성 모두에서 평가를 한다. 내전형은 발성 중 성대가 내전하는 유성음에서, 외전형은 성대가 외전하는 무성음에서 더욱 저명한 증상을 보인다. 대화 중 세 개의 문장당 하나 이상의 음성 단절이 관
찰되면 연축성 발성장애를 강하게 의심할 수 있다(probable) [2,8]. 또 열 개의 문장 중 음성 단절이 발생한 횟수에 따라 질 병의 중증도를 평가할 수 있다. 내전형 발성장애는 내전형 문 장에서, 외전형은 외전형 문장에서 부자연스럽고 발성에 상 당한 노력이 들어가는 반면, 과기능성 발성장애는 양측 모두 에서 힘이 들어가는 발성 양상을 보인다. 우리나라 언어에 알 맞은 내전형 연축성 발성장애 감별 진단 문항도 개발되어 있 다. 지속 모음과 높낮이의 변화, 숫자 세기 등에서의 증상을 확인한다[2,8,18]. 세 번째 단계는 굴곡형 비후두 내시경을 이 용하여 다른 질환을 배제하고 연축성 발성장애로 진단하게 되는 검사이다(definite). 구조적인 평가와 성대의 비대칭 여 부를 확인하고, 호흡, 기침, 헛기침, 휘파람 등의 상황에서는 정상적인 후두의 움직임을 관찰할 수 있지만, 모음을 지속하 거나 문장 읽기에서는 후두의 연축, 경련 및 진전이 발생하는 것을 확인한다[2,3].

2007년 Koufman 등은 스펙토그램을 통해 연축성 발성장 애와 근긴장성 발성장애를 감별하는 연구를 진행하였으며, 내전형 연축성 발성장애 환자는 문장 발화 중 유성음에서 갑작스러운 음성의 끊김이 많고, 불규칙하면서 넓은 수직적 간격을 보이는 양상을 보였다[10,11,16]. 일반적으로 $6 \sim 7 \mathrm{~Hz}$ 정도로 성대 내전 중 불규칙한 갑상 피열근의 수축과 음성 끊김이 관찰되어, 일정하면서 강한 본태성 음성 진전이나 다 소 약한 양상의 파킨슨에 의한 음성 진전과 차이를 보인다 $[3,18,19]$. 임상 속 감별점으로, 비자발적으로 특정 상황, 작업 에서 나타나던 발성 이상 증상이, 노래나 하품, 울기 등 비언 어적인 발성에서는 증상이 소실되면 연축성 발성장애를, 후 두 근육 긴장을 완화시키는 음성 치료로 증상이 감소되고 자 발성 여부에 관계없는 양상을 보이면 과기능성 발성장애를 의심해볼 수 있다. 그리고 발성 중 경련이나 진전의 규칙성과 추후 치료에 대한 반응 정도에 따라 일반적인 음성 진전과도 구별한다[2,3,5].

연축성 발성장애에 대한 치료는, 발병 원인이 말초신경이나 근육보다는 중추신경학적 문제인 점을 고려할 때 근본적인 원인 치료보다는 증상을 호전시키기 위한 방법으로 발전했다 $[5,11,12]$. 음성 치료는 동반되거나 속발된 기능성 발성장애를 감소하기 위한 보조적인 역할로 생각된다. 내전형 연축성 발 성장애에 대한 음성 치료의 경우, 과도한 성문 폐쇄 없이 발 성을 시작하고, 호흡 패턴을 안정화하면서 말 속도를 조절하 게 한다. 단어의 첫 음절을 갑작스럽게 발성하지 않고 자음이 나 모음을 길게 늘이면서 말하는 연습을 하면서, 말을 하는 상황에서 스트레스 조절을 교육한다[5,10,12,16]. 수술적 치료 는 1976년 Dedo가 반회후두신경 절단술을 제시하였으나 성 대마비를 유발하고 장기간 추적 관찰 중 재발이 많았다. 이 
후 후두 근육에 대한 탈신경을 위한 목적으로 레이저를 이용 한 부분적 절제술과 갑상피열근으로 가는 말단 신경분지를 자르고 목신경고리와 연결하는 선택적 신경 절제 및 문합술 등도 시행되었지만, 정상적인 구조의 변형이 불가피하고 증상 호전에 대한 예측이나 재발 등에 대한 후속 연구가 부족하다. Isshiki 등이 제2형 갑상성형술을 변형하여 만든 티타늄 고 정 수술법도 개발되었지만, 대다수 연구가 부족한 단계이다 [3,5,10,14,20-22]. 1988년 Blitzer가 연축성 발성장애에 대한 치료 방법으로 보툴리눔 독소 주입을 도입하였고, 현재까지 가장 많이 이용되면서 효과적인 방법이다. 보툴리눔 독소는 신경근 접합부에서 아세틸콜린의 분비를 억제하여 근육의 활 성도를 감소시키며, 이것을 후두 근육에 직접 주입하여 화학 적 탈신경을 유발하는 원리이다. 증상의 정도에 따라 독소의 양을 조절하고, 다양한 부위에 주입이 가능하며, 주로 내전형 은 성대 내전근인 갑상피열근, 외측 윤상피열근에 주입하고, 외전형은 성대 외전근인 후윤상 피열근에 보툴리눔 독소를 주입한다. 환자 상태에 따라 보통 3 6개월 간격으로 반복적 으로 주입한다. 주입 부위와 독소의 양에 따라 주입 직후 내전 형의 경우 쉰목소리와 흡인, 외전형의 경우 천명음이나 기도 폐쇄 증상이 일시적으로 발생할 수 있다[2,4,5,11,12,14,15,18].

\section{본태성 음성 진전}

본태성 진전은 규칙적으로 되풀이되는 진동 양상의 불수 의적 운동장애로 약 $50 \%$ 정도 우성 유전을 하는 것으로 알 려져 있다. 근긴장 이상(dystonia) 병변 없이 떨림만 나타나는 경우를 본태성 진전(essential tremor)이라고 정의한다[1,13]. 20대와 60대 두 연령층에서 호발하며 65세 이상에서 약 5\% 의 유병률을 보인다. 진전은 손가락과 손 그리고 머리 순으로 흔히 발생하며 음성 진전은 약 15 20\% 정도를 차지한다. 음 성 진전이 있는 환자 중 머리 진전을 동반한 경우도 많다. 특 정한 자세를 취하려고 하거나 유지할 때 규칙적이면서 리듬감 있는 떨림이 나타나고, 나이가 들면서 증상이 악화되는 경향 을 보인다[5,13,15]. 정확한 진단을 위해 반드시 약물 복용력 에 대한 확인이 필요하다. 이비인후과에서 자주 처방하는 갑 상선 호르몬제나 비충혈제거제, 천식 약제 등도 진전을 유발 할 수 있다[13,15]. 음성 진전은 후두 내외근과 구개 인두 근 육들이 함께 이환되는 양상으로 굴곡형 후두 내시경으로 관 찰해보면, 발성을 비롯 호흡을 할 때도 후두 전반의 규칙적 인 진동 같은 떨림을 관찰할 수 있으며, 이를 통해 연축성 발 성장애와 감별할 수 있다. 구개, 혀 기저부, 인두벽, 상후두, 진 성대 및 후두 전반으로 나눠 진전의 정도를 점수화하여 진단 할 수도 있다. 대체적으로 양측성이면서 대칭적인 양상을 보 인다[1,4,5,13,15]. 일반적으로 본태성 진전은 $4 \sim 10 \mathrm{~Hz}$ 정도의
속도로 보이는데 반해, 연축성 발성장애는 $7 \mathrm{~Hz}$ 이하의 속도 로 불규칙적인 떨림이 관찰된다. 음성 검사상 특히 지속 모음 에서 음의 높이와 강도의 규칙적이고 주기적인 변화가 잘 나 타난다. 후두근전도를 통한 연축성 발성장애와의 감별 연구 에서는, 본태성 진전 환자에서 능동적, 수동적 음성 과업 모 두 규칙적이면서 대칭적인 양상의 수축 양상을 관찰할 수 있 었다[10,11,13,15]. 수평 방향의 성대 진전이 $94 \%$ 로 가장 흔하 며, 수평과 수직 방향의 혼합 진전도 75\%로 관찰된다[13,17]. 아직까지 특별한 원인은 밝혀지지 않았지만, 뇌간의 신경 퇴 행 또는 소뇌의 과다행동 등과의 관련성이 연구되고 있으며, 해당 상병을 진단하기 위해서는 영상학적 또는 실험실 검사 에서 이상 소견이 없고, 진전을 제외한 다른 신경학적 장애를 가지고 있지 않아야 한다[5,13,15].

본태성 음성 진전에 대한 치료는 증상으로 인한 불편감을 줄여주는 것이 주 목표로, 진전의 진폭을 줄여주는 베타차단 제인 propranolol과 신경 이완제인 primidone을 시도해 볼 수 있다. 투약 초기 서맥이나 어지럼, 실조증 등 부작용이 드 물지 않게 발생할 수 있어, 소량 투여부터 시작하여 증량하는 것이 좋다. 이러한 약물 치료는 주로 사지 진전에 효과적이며, 음성 진전과 관련하여 50\% 정도에서 효과가 있는 것으로 알 려져 있다[4,5,10,13]. 증상 부위에 대한 부분적 치료로 보툴 리눔 독소 주입도 시행해 볼 수 있다. 수평 진전에는 주로 갑 상피열근과 외측 윤상피열근에 주입을 하고, 수직 진전에는 설골하연 후두 외근에 주입을 하며, 혼합 진전에는 후두 외 근에 먼저 주입 후 반응에 따라 2주 후 갑상피열근에 주입을 해볼 수 있다. 그러나 연축성 발성장애에 비해 효과가 현저하 게 감소하는 것을 관찰할 수 있으며, 이를 통해 연축성 발성 장애와 본태성 음성 진전과의 감별 진단에도 도움을 줄 수 있다. 이러한 약물적 치료에 효과가 없는 경우, 심부 뇌자극술 이나 시상절제술을 시행해볼 수 있지만, 음성 진전만으로는 시행되지 않는다[3,5,13].

\section{파킨슨병에 의한 음성 진전}

대표적인 중추신경계 퇴행성 질환인 파킨슨병은 기저핵의 흑질 선조체의 퇴행으로 인해 도파민 분비가 저하되어 운동 신경 피질의 자극이 감소되는 질환이다. 안정한 상태에서 떨 림을 보이며, 종종 걸음과 같은 특이적인 보행 이상과 운동 저하와 자세 불안정이 특징적이다[5,9,10,13]. 파킨슨병 환자의 $80 \%$ 에서 음성장애를 호소하는데, 입술과 턱 부위의 강직으 로 인해 조음 범위가 축소되어 높낮이와 강세 변화가 부족한 단조로운 음조가 발생하고 발음이 불분명해지며, 발화의 시 작이 어려운 증상을 보인다. 후두내시경상 성대 위축이 보이 면서 발성 시 성대의 중간 부위가 열리고, $4 \sim 6 \mathrm{~Hz}$ 정도의 상 
대적으로 느린 진동이 나타난다. 후두 감각 저하로 인해 기침 이나 흡인 반사가 잘 일어나지 못하고 인후두 내 분비물을 원 활하게 처리하지 못해 상당량이 고여 있는 경우가 많다[3,5, 13]. 일차적인 치료는 도파민 전구체인 L-dopa의 경구 투여 이며, 일부 연구에서 약제 사용 시 jitter의 감소 효과가 있음 을 발표하였지만 음성장애 해소에는 전반적으로 효과가 미미 한 것으로 알려져 있다. Lee Silverman 음성 치료는 파킨슨병 음성장애 환자에 대한 대표적인 음성 치료 방법으로, 발화 노력 향상을 통해 음성 강도와 발음의 정확도를 증가시키고 연하 작용에도 도움을 준다[2,4,5,10,15,23].

\section{근긴장성 발성장애}

과기능성 발성장애의 대표적인 질환인 근긴장성 발성장애 는 발성 시 후두 내근과 외근의 지나친 긴장으로 인해 음질 과 음역이 감소하고 불규칙적인 진동을 유발하여 떨리는 음 성이 나타나기도 하며 구강 및 안면 근육에 영향을 주면 조 음에도 문제가 발생할 수 있다[10,11,17]. 구조적 또는 신경학 적 병변 없이 후두 내외근에 과도한 긴장이 발생하여 성대 진 동과 유연성에 문제가 발생한 경우 원발성 근긴장성 발성장 애로 진단하며, 성대 점막 병변, 성문 폐쇄 부전 등으로 인한 보상 기전으로 과도한 근긴장이 발생한 경우 속발성으로 진 단한다. 이환되는 부위에 따라 다양한 증상을 보일 수 있으 며, 음성장애가 아닌 후두 이물감이나 경부 통증만을 호소하 는 경우도 있다. 이중 음성과 음성 프라이(vocal fry)가 관찰 될 수 있다. 연축성 발성장애 의심 환자와의 감별 기준으로 지속적인 모음이나 대화 등 다양한 음성 과업에서도 일관적 인 과기능성 발성장애를 보이며, 적절한 후두 마사지와 통증 경감 및 음성 치료, 원인이 되는 질환에 대한 치료로 인해 음 성 증상이 호전되는 것을 볼 수 있다[3,11,13,14,16,17].

\section{감별 진단}

말을 시작하는 것을 힘들어하고 떨리거나 부쩍 약해진 발 성을 보이는 환자가 내원하면, 주관적인 병력 청취는 물론, 청 지각적인 판단과 함께 환자의 동반 증상을 확인한다. 발성과 호흡 근육을 지배하는 중추성 및 말초성 근신경계 이상으로 성대가 떨리거나, 움직임이 부자연스러워지는 신경성 발성장 애 중 연축성 발성장애, 본태성 음성 진전 및 파킨슨병에 의 한 음성 진전은 다소 비슷한 증상으로 인해 외래 진료 환경 에서 감별에 어려움이 있다[15,17,18].

떨리는 음성이 다소 쥐어짜는 듯, 힘이 들어가면서 불규칙 하게 떨리고 끊긴다면 내전성 연축성 발성장애를, 리드미컬한 규칙성을 보이면서 음성이 끊기고 불안정한 떨림이 있다면 본태성 음성 진전을 의심해볼 수 있다. 특정한 말 과제(유무
성음 문장 등), 전화 통화 및 글 읽기를 수행할 때는 음성 떨 림과 끊김이 발생하지만, 웃기, 울기 및 하품 등 비언어적 발 성과 노래 부르기에서는 정상적인 발성을 보인다면 연축성 발성장애를 의심해볼 수 있다. 그러나 다양한 말 과제 및 여 러 생리학적 발성과 지속 모음 등 발성의 전반에서 일정한 떨 림이 계속 관찰되고 발화의 시작부터 끝까지 지속된다면 본 태성 음성 진전을 의심해볼 수 있다. 연축성 발성장애는 성 대의 불수의적 운동에 직접적으로 관여하는 근육에만 주로 이환되는 데 반해, 본태성 음성 진전은 성대를 비롯 피대근 및 인후두의 전반적인 근육을 침범한다. 그리고 손이나 머리 의 진전도 동반되는 경우도 많다[3,15,17,18]. 떨림의 진폭을 감 소시키기 위해 베타차단제 propranolol과 신경 이완제 primidone을 사용하면 본태성 음성 진전의 경우, 약 $50 \%$ 정도에 서 호전을 보일 수 있다. 화학적 탈신경을 통해 근육 활성도를 감소시키는 목적으로 보툴리눔 독소를 해당 근육에 주입하게 되면, 연축성 발성장애의 경우 적절한 용량과 시기 조절로 증 상 완화에 상당한 효과를 볼 수 있는 반면, 본태성 음성 진전 의 경우 경구 약물 제재보다 효과가 낮은 것으로 알려져 있 다. 이러한 치료 결과 평가도 정확한 감별 진단과 치료에 도 움을 줄 수 있다[3,4,14,18].

쥐어짜거나 힘들게 발성을 시작하는 환자의 경우, 지속 모 음이나 유무성음 문장 읽기를 하면서 음성 단절의 정도를 평 가하며 연축성 발성장애와 근긴장성 발성장애를 감별할 수 있다. 고음이나 가성 발성에서 음성 단절이 감소하는 경향을 보이면 연축성 발성장애, 고음과 관계없는 양상이지만, 적절 한 후두 마사지와 음성 치료 병행으로 증상이 호전된다면 근 긴장성 발성장애를 의심해볼 수 있다. 두 가지 질환의 스펙토 그램을 비교하면, 내전형 연축성 발성장애에서 문장 발화 시 유성음에서 갑작스러운 음성 단절과 불규칙하면서 넓은 수 직적 간격(vertical striation)을 보이면서 상대적으로 더 선명 한 포먼트가 형성된다. 고주파수 대역에서는 근긴장성 발성 장애에서 잡음 발생이 현저하게 나타난다[3,4,11,14,16,18].

\section{결 론}

연축성 발성장애와 본태성 음성 진전 및 파킨슨병에 의한 음성 진전은, 발화의 시작이 어렵고 음성이 떨리는 다소 비슷 한 증상을 보이지만, 질환의 원인과 그에 따른 치료가 상이하 다. 성대가 과기능성 긴장과 동반된 떨림을 보이면, 근긴장성 발성장애와의 감별도 필요하다. 특정한 말 과제 수행에 대한 다각적인 평가와 감별 사항에 대한 이해를 통해, 음성 진전 환자에 대한 정확한 진단과 효과적인 치료에 도움이 될 것으 로 사료된다. 
중심 단어: 연축성 발성장애, 음성 진전, 감별진단.

Acknowledgments

None.

Conflicts of Interest

The author has no financial conflicts of interest.

\section{REFERENCES}

1. Kirke DN, Battistella G, Kumar V, Rubien-Thomas E, Choy M, Rumbach A, et al. Neural correlates of dystonic tremor: a multimodal study of voice tremor in spasmodic dysphonia. Brain Imaging Behav 2017;11(1):166-75.

2. Ludlow CL, Adler CH, Berke GS, Bielamowicz SA, Blitzer A, Bressman SB, et al. Research priorities in spasmodic dysphonia. Otolaryngol Head Neck Surg 2008;139(4):495-505.

3. Ludlow CL, Domangue R, Sharma D, Jinnah HA, Perlmutter JS, Berke $\mathrm{G}$, et al. Consensus-based attributes for identifying patients with spasmodic dysphonia and other voice disorders. JAMA Otolaryngol Head Neck Surg 2018;144(8):657-65.

4. Patel PN, Kabagambe EK, Starkweather JC, Keller M, Ahmed ZA, Gruber SC, et al. Defining differences in patient characteristics between spasmodic dysphonia and laryngeal tremor. Laryngoscope 2019;129(1):170-6.

5. Kwon TK, Son HY. Movement disorders affecting the larynx. J Korean Soc Laryngol Phoniatr Logop 2010;21(1):22-6.

6. Kwon MS, Sim HS, Chung SJ, Lee JH. A case of spasmodic dysphonia after a right hemispheric lesion. Dementia and Neurocognitive Disorders 2003;2(1):84-7.

7. Kim YH. Laryngeal neurophysiology. Korean J Otolaryngol-Head Neck Surg 2003;46(10):799-807.

8. Yang Y. Spasmodic dysphonia. Korean J Otolaryngol-Head Neck Surg 2010;53(9):519-26.

9. Kim SW, Park YH. Resting-state functional connectivity mediating for phonation by the thalamus in Parkinson's disease. Commun Sci Disord 2020;25(2):470-9.

10. Kim SY, Lee SH. Differential diagnosis between neurogenic and functional dysphonia. J Korean Soc Laryngol Phoniatr Logop 2017;28(2): 71-8.

11. Rees CJ, Blalock PD, Kemp SE, Halum SL, Koufman JA. Differentiation of adductor-type spasmodic dysphonia from muscle tension dysphonia by spectral analysis. Otolaryngol Head Neck Surg 2007;137(4):
576-81.

12. Ko H, Choi HS, Lim SE, Choi Y. The aspect of voice characteristics change after botulinum toxin-a injection in patients with adductor spasmodic dysphonia according to vocal tremor. Phonetics Speech Sci 2012;4(4):95-107.

13. Gillivan-Murphy P, Miller N. Voice tremor: what we know and what we do not know. Curr Opin Otolaryngol Head Neck Surg 2011;19(3): 155-9.

14. Pearson EJ, Sapienza CM. Historical approaches to the treatment of adductor-type spasmodic dysphonia (ADSD): review and tutorial. NeuroRehabilitation 2003;18(4):325-38.

15. Barkmeier JM, Case JL, Ludlow CL. Identification of symptoms for spasmodic dysphonia and vocal tremor: a comparison of expert and nonexpert judges. J Commun Disord 2001;34(1-2):21-37.

16. Roy N, Whitchurch M, Merrill RM, Houtz D, Smith ME. Differential diagnosis of adductor spasmodic dysphonia and muscle tension dysphonia using phonatory break analysis. Laryngoscope 2008;118(12): 2245-53.

17. Imamura R, Tsuji DH. Adduction spasmodic dysphonia, vocal tremor and muscular tension dysphonia: is it possible to reach a differential diagnosis? Braz J Otorhinolaryngol 2006;72(4):434.

18. Cho JK, Choi SH, Lee SH, Jin SM. Development of differential diagnosis scale items for adductor spasmodic dysphonia and evaluation of clinical availability. J Korean Soc Laryngol Phoniatr Logop 2019; 30(2):112-7.

19. Choi HS, Lee JH, Kim IS, Koh YW, Oh JS, Yoon HC, Choi SH. The acoustic and aerodynamic aspects of patients with spasmodic dysphonia. J Korean Soc Laryngol Phoniatr Logop 2000;11(1):98-103.

20. Tsuji DH, Takahashi MT, Imamura R, Hachiya A, Sennes LU. Endoscopic laser thyroarytenoid myoneurectomy in patients with adductor spasmodic dysphonia: a pilot study on long-term outcome on voice quality. J Voice 2012;26(5):666.e7-12.

21. Schuering JHC, Heijnen BJ, Sjögren EV, Langeveld APM. Adductor spasmodic dysphonia: botulinum toxin a injections or laser thyroarytenoid myoneurectomy? A comparison from the patient perspective. Laryngoscope 2020;130(3):741-6.

22. Kim HS, Choi HS, Lim JY, Choi YL, Lim SE. Radiofrequency thyroarytenoid myothermy for treatment of adductor spasmodic dysphonia: how we do it. Clin Otolaryngol 2008;33(6):621-5.

23. Sanabria J, Ruiz PG, Gutierrez R, Marquez F, Escobar P, Gentil M, et al. The effect of levodopa on vocal function in Parkinson's disease. Clin Neuropharmacol 2001;24(2):99-102. 